\title{
Protective effect of ginkgolide B against isoproterenol- induced chronic heart failure in rats via modulation of Nrf2 and HO-1 signaling pathways
}

\author{
Lu Hui Zhi ${ }^{1}$, Wang Bin $\mathbf{R u}^{2}$, Tan Yun ${ }^{1}$, Dong Hui ${ }^{1}$, Liu $\mathrm{Li}^{2 \star}$ \\ ${ }^{1}$ Department of Critical Care Medicine and Emergency, ${ }^{2}$ Department of Ear-Nose-Throat (ENT), Tongren Hospital of Wuhan \\ University (Wuhan Third Hospital), Wuhan 430074, China
}

*For correspondence: Email: LizbethTorresqbl@yahoo.com; Tel: +86278884 3447

\begin{abstract}
Purpose: To determine the protective effect of ginkgolide $B(G B)$ against isoproterenol (ISO)-induced chronic heart failure in a rat model.

Methods: A total of 32 male Wistar rats were randomly divided into 4 groups. Rats in control group received only saline, while rats in GB alone group were injected with GB at a dose of $20 \mathrm{mg} / \mathrm{kg}$ body weight (bwt) intraperitoneally (i.p). Another group of rats was injected with ISO subcutaneously (s.c.) at a dose of $85 \mathrm{mg} / \mathrm{kg}$ for 2 days (ISO group). Rats in the GB+ISO group were administered GB at a dose of $20 \mathrm{mg} / \mathrm{kg}$, i.p., for 7 days prior to exposure to ISO s.c. at a dose of $85 \mathrm{mg} / \mathrm{kg}$.

Results: Rats pre-treated with GB for 7 days prior to ISO exposure showed a significant decrease in cardiac infarct size, and marked decreases in the levels of cardiac biomarkers, inflammatory and apoptotic biomarkers, and lipid peroxidation $(p<0.05)$, but significant improvement in the levels of endogenous antioxidants $(p<0.05)$. In addition, GB administration resulted in marked increases in the protein expression levels of heme oxygenase-1 (HO-1) and Nrf2 in cardiac tissue $(p<0.05)$.

Conclusion: These results indicate that pre-treatment of chronic heart failure rats with $G B$ for 7 consecutive days considerably lowered inflammatory and apoptotic markers via upregulation of Nrf2/HO-1 signaling pathway. Thus, GB has cardioprotective potential in humans.
\end{abstract}

Keywords: Ginkgolide B, Nrf2/HO-1, Inflammatory markers, Apoptotic markers, Antioxidants

\begin{abstract}
This is an Open Access article that uses a fund-ing model which does not charge readers or their institutions for access and distributed under the terms of the Creative Commons Attribution License (http://creativecommons.org/licenses/by/4.0) and the Budapest Open Access Initiative (http://www.budapestopenaccessinitiative.org/read), which permit unrestricted use, distribution, and reproduction in any medium, provided the original work is properly credited.
\end{abstract}

Tropical Journal of Pharmaceutical Research is indexed by Science Citation Index (SciSearch), Scopus, International Pharmaceutical Abstract, Chemical Abstracts, Embase, Index Copernicus, EBSCO, African Index Medicus, JournalSeek, Journal Citation Reports/Science Edition, Directory of Open Access Journals (DOAJ), African Journal Online, Bioline International, Open-J-Gate and Pharmacy Abstracts

\section{INTRODUCTION}

Myocardial infarction (MI) or heart attack (HA) is one of the most predominant and deadly forms of ischemic heart disease (IHD), based on the fact that it claims more lives than any other cardiovascular disease (CVD). A report from the World health organization (WHO) indicated that approximately 23 million people worldwide are affected directly or indirectly by $\mathrm{MI}[1,2]$. Similarly, the National Center for Cardiovascular Diseases in China reported that the number of CVD patients particularly MI patients, is continuously on the increase. Moreover, the cost of treating $\mathrm{MI}$ reached 2.3 billion US dollars in 2015, an indication of the indirect and considerable economic burden of the disease on China $[3,4]$. 
Myocardial infarction is caused by lack of sufficient blood supply to the heart muscles, leading to necrosis or apoptosis of the myocardium (heart muscle). This is accompanied by numerous pathophysiological and biochemical changes including hypoxia, hyperlipidemia, oxidative stress, and inflammatory responses $[5,6]$. The current treatment for $\mathrm{Ml}$ is limited by the fact that many anti-MI medications result in serious adverse effects. Hence, many researchers have focused on natural antioxidant and anti-inflammatory agents for treating or managing MI-related conditions [7,8].

Ginkgo biloba is one of the oldest trees known to man. Its bark and leaves are traditionally recommended for improving immune and cognitive function, and for treating the common cold, tinnitus and migraine [9]. Ginkgolide B (GB; $\mathrm{C}_{20} \mathrm{H}_{24} \mathrm{O}_{10}$ ) is one of the major diterpenoids extracted from the leaves of the popular Ginkgo biloba tree. Ginkgolide B exerts an extensive range of pharmacological effects such as antiinflammatory, anti-atherosclerotic, anti-tumor, antioxidant as well as hepatoprotective and neuroprotective properties [10-12]. Moreover, GB inhibits NF-KB activation, and protects the brain and heart from ischemia/reperfusion injury in in vitro and in vivo studies [13-15]. Studies have also shown that ginkgolide $B$ exhibits cardioprotective effect against doxorubicininduced cardiotoxicity via regulation of oxidative status [16]. Based on previous reports, it is clear that $\mathrm{GB}$ shows potent cardioprotective effect in various cardiotoxicity models as well as in ischemia/reperfusion conditions. Nonetheless, the mechanism behind the cardioprotective property of GB against isoproterenol-induced heart failure or myocardial infarction is not fully understood. The current animal study was aimed at investigating the protective effect of $\mathrm{GB}$ against isoproterenol-induced chronic heart failure in the rat.

\section{EXPERIMENTAL}

\section{Chemicals}

Ginkgolide B (GB) and isoproterenol (ISO) hydrochloride were purchased from SigmaAldrich (MA, USA). Other chemicals and reagents used in this study were of either HPLC or analytical grade.

\section{Experimental rats and ethical approval}

The thirty-two male Wistar albino rats of mean weight $220 \pm 10 \mathrm{~g}$ were bought from Experimental Animal Lab Vendor; Beijing, China.
The rats were raised in a polycarbonated cage at optimal temperature of $21 \pm 2{ }^{\circ} \mathrm{C}$ and relative humidity of $55-60 \%$. The animals were handled with utmost care in line with the guidelines set by NRC (Care and handling of laboratory animals) to minimize animal suffering [17]. The animal ethical committee of Wuhan University gave approval for this animal study (approval no. WU/2019-45/3). All animal experiments were conducted at Wuhan University Animal house from March to April, 2018.

\section{Animal grouping}

Healthy male Wistar rats $(n=32)$ were randomly divided into four groups (8 rats/group). Rats in the control group received only saline, whereas rats in the GB group were injected $G B$ at a dose of $20 \mathrm{mg} / \mathrm{kg}$ bwt i.p. for 7 days. Rats in ISO group (MI group) were injected s.c. with ISO at a dose of $85 \mathrm{mg} / \mathrm{kg}$ bwt [7] for 2 days (on the $8^{\text {th }}$ and $9^{\text {th }}$ days), while rats in GB + ISO group were administered $\mathrm{GB}$ at a dose of $20 \mathrm{mg} / \mathrm{kg}$ i.p. for 7 days prior to ISO exposure ( $85 \mathrm{mg} / \mathrm{kg}$ bwt).

\section{Sample collection and analysis}

On day 10 , the rats were euthanized using isoflurane, and blood samples were collected in non-heparinized tubes for preparation of serum samples. The heart tissues were excised, and small portions were sliced and kept at $-80^{\circ} \mathrm{C}$ for use in triphenyl tetrazolium chloride (TTC) staining. The remaining heart samples were homogenized in Tris- $\mathrm{HCl}$ buffered solution $\mathrm{pH}$ 7). The homogenates were centrifuged at 12000 $\mathrm{g}$ at $4{ }^{\circ} \mathrm{C}$ for $15 \mathrm{~min}$, and the resultant supernatants were used for biochemical assays.

\section{Determination of antioxidant status and lipid peroxidation}

Heart tissue homogenate was used to assay the activities of various endogenous antioxidants and levels of lipid peroxidation products. The levels of malondialdehyde (MDA, a lipid peroxidation product) was measured using an enzymatic assay kit (Kangchen Biotechnology (Shanghai, China) based on the manufacturer's instruction. The activities of cardiac antioxidants [catalase (CAT) and superoxide dismutase (SOD)] were assayed using enzymatic assay kit purchased from Nanjing Bioengineering Institute (Nanjing, China), in line with the manufacturer's protocol.

\section{Assessment of cardiac biomarkers}

Serum lactate dehydrogenase (LDH), creatine kinase isoform MB (CK-MB), and cardiac troponin $\mathrm{T}(\mathrm{cTn} \quad \mathrm{T})$ were assayed using 
commercial ELISA kits (MYBioSource, CA, USA; for LDH and CK-MB; and Teco Diagnostics, CA, USA for cTn T).

\section{Evaluation of inflammatory markers}

Nuclear and cytosolic fractions from heart tissue homogenate were separated with commercial Nuclear/Cytosolic fractionation kit (Cellbiolabs Inc, CA, USA) using ultracentrifugation technique. Inflammatory markers (IL-6, IL-1 $\beta$ and TNF- $\alpha$ ) were measured in the cytosolic fraction of heart tissue homogenate with commercial rat specific ELISA kit (Thermo Fisher Scientific, MA, USA).

The level of NF-KB p65 was measured in the nuclear fraction using commercial ELISA NF-KB (p65) Transcription Factor Assay kit from Cayman Chemical (MI, USA), based on the manufacturer protocol.

\section{Assay of apoptosis markers}

The major apoptotic markers i.e. caspase- 3 and caspase-9 were assayed in cardiac tissue homogenate using a commercial assay kit from Abcam (Cambridge, UK) based on manufacturer's instructions.

\section{Determination of protein expression}

The cardiac homogenate was used to determine the protein expressions of $\mathrm{HO}-1$ (in cytosolic fraction) and Nrf2 (in nuclear fraction). The assay technique used was western blotting. The cardiac tissue homogenate was lysed using RIPA buffered solution containing various proteases, followed by determination of protein level using bicinchomninic acid (BCA) protein assay kit (BioVision Inc., CA, USA). An equal amount of protein $(50 \mu \mathrm{g})$ from each group was resolved with $8 \%$ SDS-polyacrylamide gel electrophoresis apparatus, and transferred onto PVDF membrane.

After blocking non-specific binding, the membrane was probed overnight at $4{ }^{\circ} \mathrm{C}$ with the following primary antibodies: anti-Nrf2, anti-HO-1 (1:1000 dilution), anti-histone H3 (1:1000 dilution) and anti- $\beta$ actin (1:1000 dilution) (Santa Cruz Biotechnology Inc., TX, USA). Thereafter, the membrane was incubated with rabbit polyclonal anti-horseradish peroxidase (HRP) secondary antibody (1:10000 dilution) at $37^{\circ} \mathrm{C}$ for $1 \mathrm{~h}$. The protein bands in the PVDF membrane were developed using enhanced chemiluminescence (ECL) kit, and the protein expression was measured using image analyzing software.

\section{Statistical analysis}

Data are shown as mean \pm standard error of mean (SEM). Statistical analysis for determination of significant differences amongst groups was carried out with one-way ANOVA, followed by Tukey's multi-comparison test. All statistical analyses were done with GraphPad Prism (Ver 6; Graphpad Software Inc, CA, USA. Significant difference was set at $p<0.01$.

\section{RESULTS}

\section{Effect of GB on cardiac infarct size}

Figure 1 depicts the effect of GB on cardiac infarct size in the control and experimental rats. The infarct size of ISO-treated rats was significantly higher than that of control rats $(p<$ 0.01 ). In contrast, rats injected i.p. with $G B$ at a dose of $20 \mathrm{mg} / \mathrm{kg}$ of GB for 7 days prior to ISO injection (GB + ISO group) had marked decreases in infarct size, relative to ISO-treated MI model group $(p<0.01)$.

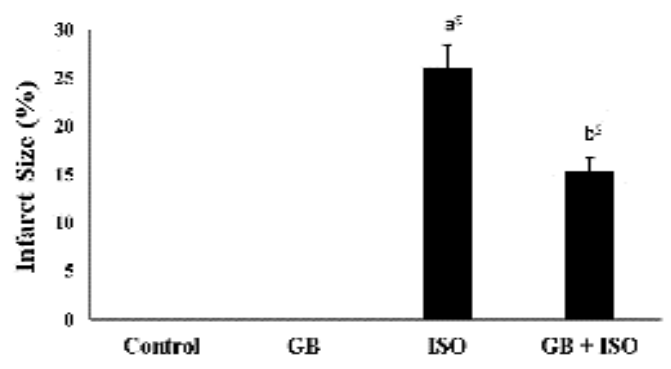

Figure 1: Effect of GB on cardiac infarct size in control and experimental rats. Values are expressed as the mean \pm SEM; ${ }^{a} p<0.01$ ), control versus ISO group; ${ }^{\mathrm{b} \$} p<0.01, \mathrm{~GB}+\mathrm{ISO}$ versus ISO group

\section{Effect of GB on cardiac antioxidants and lipid peroxidation}

A pronounced increase $(p<0.01)$ in MDA was observed in ISO-treated rats (Table 1). Moreover, the activities of CAT and SOD were significantly decreased in ISO-exposed rats $(p<$ $0.01)$. However, rats pre-treated with $G B(G B+$ ISO) had significxant reductions in MDA levels, as well as markedly elevation in the activities of CAT and SOD, when compared with ISOinduced group $(p<0.01)$.

\section{Effect of GB on cardiac diagnostic markers}

The effect of GB on cardiac diagnostic marker enzymes in control and experimental rats are shown in Table 2. 
Table 1: Effect of GB on heart lipid peroxidation and antioxidant levels in control and experimental rats

\begin{tabular}{lllll}
\hline Parameter & Control & GB & ISO & GB+ISO \\
\hline MDA (nmols/mg protein) & $0.44 \pm 0.08$ & $0.45 \pm 0.06$ & $0.78 \pm 0.09^{\mathrm{a} \$}$ & $0.57 \pm 0.06^{\mathrm{b \$}}$ \\
CAT (U/mg protein) & $12.40 \pm 2.45$ & $12.72 \pm 1.43$ & $8.74 \pm 0.10^{\mathrm{a} \$}$ & $10.81 \pm 1.44^{\mathrm{b} \$}$ \\
SOD (U/mg protein) & $4.89 \pm 0.63$ & $5.01 \pm 0.70$ & $3.23 \pm 0.40^{\mathrm{a} \$}$ & $4.05 \pm 0.75^{\mathrm{b} \$}$ \\
\hline Values are expressed as mean \pm SEM; $\left.{ }^{\mathrm{a} \$} p<0.01\right)$, control versus ISO group; ${ }^{\mathrm{b} \$} p<0.01$, GB+ISO versus ISO \\
group
\end{tabular}

Table 2: Effect of GB on heart diagnostic biomarkers in control and experimental rats

\begin{tabular}{|c|c|c|c|c|}
\hline Parameter & Control & GB & ISO & GB+ISO \\
\hline $\mathrm{LDH}(\mathrm{IU} / \mathrm{L})$ & $68.92 \pm 8.10$ & $70.12 \pm 9.34$ & $134.74 \pm 18.03^{\mathrm{a} \$}$ & $85.56 \pm 10.22^{\mathrm{b} \$}$ \\
\hline CK-MB (IU/L) & $59.29 \pm 7.20$ & $60.92 \pm 7.45$ & $130.86 \pm 20.00^{\mathrm{a} \phi}$ & $78.00 \pm 10.05^{\mathrm{D} \phi}$ \\
\hline cTn T (ng/mL) & $0.45 \pm 0.07$ & $0.47 \pm 0.05$ & $1.33 \pm 0.35^{\mathrm{a} \$}$ & $0.64 \pm 0.09^{\mathrm{b} \$}$ \\
\hline
\end{tabular}

There were significant increases in the activities of cardiac diagnostic marker enzymes i.e. CK$\mathrm{MB}, \mathrm{LDH}$, and $\mathrm{CTn} \mathrm{T}$ in ISO-exposed MI model rats $(p<0.01)$. However, these increases were significantly reversed to normal levels by treatment with $\mathrm{GB}$ i.e. in the $\mathrm{GB}+\mathrm{ISO}$ group $(p<$ 0.01).

\section{Effect of $\mathrm{GB}$ on cardiac inflammatory biomarkers}

As shown in Figure 2, the mean levels IL-6, IL$1 \beta$, TNF- $\alpha$ and NF-kB p65 subunit in cardiac tissue homogenate were significantly enhanced $(p<0.01)$ in rats exposed to ISO (MI model), relative to control rats. However, administration of $\mathrm{GB}$ before ISO injection (GB + ISO) led to considerable decreases in the levels of IL-6, IL$1 \beta$, TNF- $\alpha$, and NF-KB p65 subunit, when compared with ISO-exposed group $(p<0.01)$.

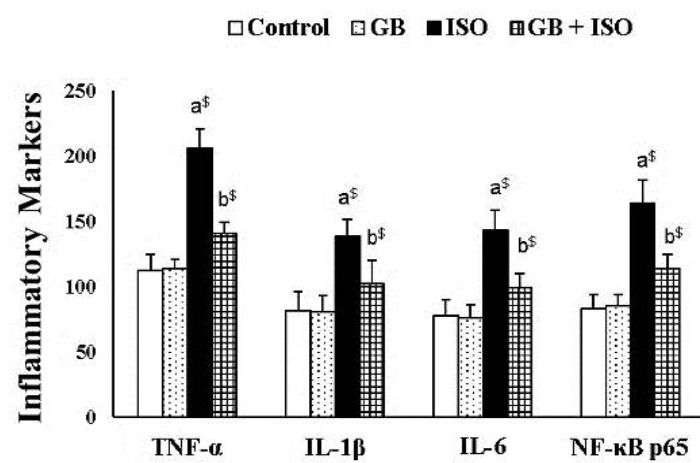

Figure 2: Effect of GB on cardiac inflammatory biomarkers (pro-inflammatory cytokines) in control and experimental rats. Values are expressed as mean \pm SEM; ${ }^{\mathrm{a} \$} p<0.01$ ), control versus ISO group; ${ }^{\mathrm{b} \$} p<0.01$, $\mathrm{GB}+\mathrm{ISO}$ versus ISO group

\section{Effect of GB on cardiac apoptotic biomarkers}

Figure 3 shows the effect of $\mathrm{GB}$ on cardiac apoptotic markers (caspase-3 and caspase 9) in control and experimental rats. The activities of caspase-3 and caspase-9 were significantly upregulated in rats injected with ISO at a dose of $85 \mathrm{mg} / \mathrm{kg}$ (Ml model), when compared with control rats $(p<0.01)$. In contrast, rats injected with GB for 7 days before ISO-exposure (GB + ISO) showed a considerable decline in the activity of caspases-3 and caspase- 9 , relative to ISO-exposed rats $(p<0.01)$.

$$
\square \text { Control घGB IISO } \mathrm{GGB}+\text { ISO }
$$

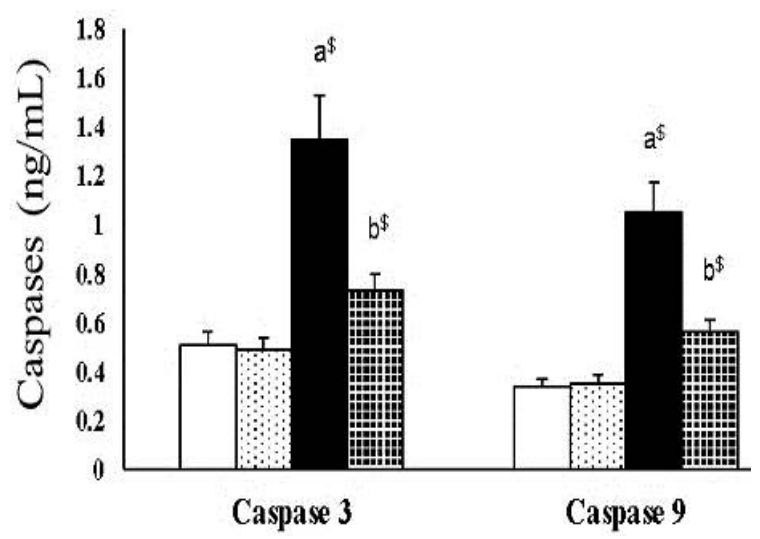

Figure 3: Effect of GB on cardiac apoptotic markers (caspase-3 and caspase-9) in control and experimental rats. Values are expressed as the mean \pm SEM. Values are expressed as mean \pm SEM; ${ }^{a \$} p<$ 0.01 ), control versus ISO group; ${ }^{b \$} p<0.01, \mathrm{~GB}+\mathrm{ISO}$ versus ISO group

\section{Effect of GB on protein expressions of $\mathrm{HO}-1$ and Nrf2}

The protein expression levels of $\mathrm{HO}-1$ (in cytosolic fraction) and Nrf2 (in nuclear fraction) were markedly upregulated in rats exposed to ISO, when compared with control rats $(p<0.05$; Figure 4). Rats administered GB prior to ISOtreatment (GB + ISO rats) had higher levels of protein expressions of $\mathrm{HO}-1$ and Nrf2 than ISOexposed rats. 


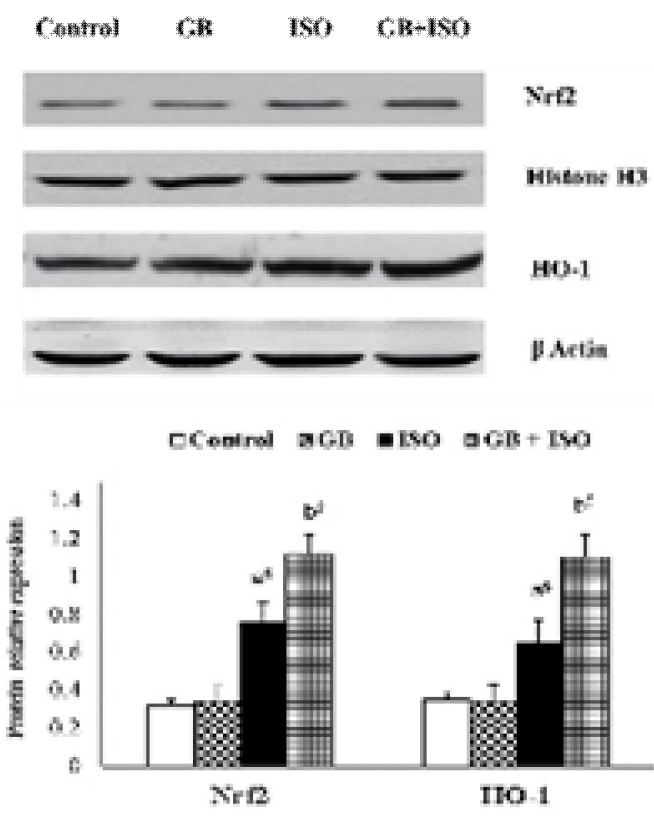

Figure 4: Effect of GB on cardiac protein expressions of Nrf2 and HO-1 in control and experimental rats; ${ }^{\mathrm{a} \$} p$ $<0.01$ ), control versus ISO group; ${ }^{b \$} p<0.01$, GB+ISO versus ISO group

\section{DISCUSSION}

The results obtained in this animal study have highlighted the cardioprotective potential of GB through significant decreases in cardiac infarct size and reduced levels of cardiac markers, inflammatory biomarkers and biomarkers of apoptosis. Moreover, GB decreased lipid peroxidation and brought about significant increases in the activities of endogenous antioxidants through upregulation of protein expressions of Nrf2 and $\mathrm{HO}-1$. The hallmark of myocardial infarction is increased infarct size in the myocardium, which results in death of cardiomyocytes [6]. Thus, the effect of GB on cardiac infarct size was determined using TTC staining procedure. Rats treated with $\mathrm{GB}$ at a dose of $20 \mathrm{mg} / \mathrm{kg}$ had substantial decreases in the infarct size. Similarly, Zhang his co-workers have reported that GB treatment significantly reduced infarct size in a myocardial ischemia/reperfusion injury (Ml/RI) rat model [14].

Oxidative stress and inflammatory response constitute major pathophysiologies of $\mathrm{MI}$ [5]. Thus, in this study, the effect of GB on cardiac antioxidants and lipid peroxidation was measured by assay of the antioxidant enzymes CAT and SOD. Injection of rats with GB i.p. for 7 days led to significant improvement in antioxidant capacity and lower MDA production owing to potent free radical scavenging effect of GB. Recently, $\mathrm{Li}$ and his colleagues reported that administration of $G B$ markedly enhanced SOD and CAT activities, and significantly lowered the lipid peroxidation product (MDA) in a rat model of hypoxia-induced neuronal damage [18].

Myocardial infarction (MI) results in damage to myocardiocyte membranes and the release of cardiac diagnostic marker enzymes (LDH, CK$\mathrm{MB}$ and CTnT) into the blood. Thus, these enzymes are used as diagnostic parameters for monitoring the degree of MI [19]. In the present study, rats exposed to ISO had increased serum levels of the cardiac marker enzymes CK-MB, LDH and CTnT due to increased myocardiocyte damage. However, GB treatment reversed these increases owing to its antioxidant and anti-lipid peroxidation properties. A study has shown that GB significantly reduced the levels of cardiac troponin $\mathrm{T}$ and $\mathrm{LDH}$ in a rat model of myocardial I/R [13].

Inflammation is one of the pivotal biochemical responses during MI. The levels of various inflammatory markers were markedly increased in ISO-treated rats owing to the activation of the $\mathrm{NF}-\mathrm{kB}$ signaling cascade, thereby triggering excessive free radical generation. Pre-treatment of rats with GB significantly decreased the levels of IL-6, IL-1 $\beta$ TNF- $\alpha$, and NF-KB p65 subunit by inhibiting the activation of the NF-KB signaling pathway. It has been demonstrated that $\mathrm{GB}$ supplementation suppressed the activation of NF-KB p65 and triggered inflammatory response in various animal models $[14,20]$.

Apoptosis (programmed cell death) is directly associated with various pathophysiological conditions, especially $\mathrm{Ml}$. In this study, rats exposed ISO had increased levels of caspase 3 and caspase 9 due to enhanced oxidative stress and inflammatory response, leading to upregulation of the caspase cascade and cardiomyocyte apoptosis. However, these changes were reversed by pre-treatment of the rats with GB for 7 consecutive days. These results are in agreement with the results reports by $\mathrm{Gu}$ and coworkers, who found that GB markedly altered caspase cascade-related proteins in a mouse model of cerebral ischemia/reperfusion injury [15].

Nuclear transcriptional factor (Nrf2) plays a major role in the regulation of redox homeostasis by inducing various antioxidants and detoxifying enzymes including $\mathrm{HO}-1$ and $\mathrm{NADPH}$ : quinone oxidoreductase 1 (NQO-1) [21]. The protein expressions of $\mathrm{Nrf} 2$ and $\mathrm{HO}-1$ were significantly upregulated in ISO-exposed rats, resulting in protection of the myocardium from further damage (cytoprotective effect) triggered by 
normal physiological redox response. The GB treatment also triggered on cytoprotective redox mechanism and resulted in further upregulation of Nrf2 and HO-1 protein expressions, and increased production of various antioxidant enzymes. Likewise, Jiang and co-workers have demonstrated that treatment with GB markedly upregulated protein expressions of $\mathrm{Nrf} 2$ and $\mathrm{HO}$ 1 in the renal tissue of diabetic rats [10].

\section{Limitations of the study}

This study has some limitations: the left ventricular function was not subjected to electrocardiography and histopathological examination, and other signaling pathways (PI3K/Akt and GSK) were not investigated, due to financial constraints.

\section{CONCLUSION}

Pre-treatment of rats with ISO-induced heart failure using GB for 7 consecutive days resulted in marked lowering of lipid peroxidation, inflammatory biomarkers and apoptotic indices, with enhanced antioxidant status via upregulation of Nrf2/HO-1 signaling pathway. Thus, GB exerts strong cardioprotective potential and might be beneficial in the clinical management of $\mathrm{Ml}$ related conditions. Nevertheless, clinical trials are needed to ascertain the cardioprotective and other effects of GB in humans.

\section{DECLARATIONS}

\section{Acknowledgement}

This animal study was financially aided by Basic Project Fund Wuhan University (no. BPFWU136/2018).

\section{Conflict of interest}

No conflict of interest is associated with this study

\section{Contribution of authors}

We declare that this work was done by the authors named in this article and all liabilities pertaining to claims relating to the content of this article will be borne by the authors. Lu Hui Zhi (LHZ), Dong Hui (DH) and Liu Li (LL) designed and concepted this animal experiment. LL, WB, and $\mathrm{LHZ}$ conducted most of the animal experiments. $\mathrm{LL}$ and $\mathrm{LHZ}$ involved in drafting and editing this research paper. Wang Bin ru (WB) and Tan Yun aided in statistical analysis.

\section{Open Access}

This is an Open Access article that uses a funding model which does not charge readers or their institutions for access and distributed under the terms of the Creative Commons Attribution License (http://creativecommons.org/licenses/by/ 4.0) and the Budapest Open Access Initiative (http://www.budapestopenaccessinitiative.org/rea d), which permit unrestricted use, distribution, and reproduction in any medium, provided the original work is properly credited.

\section{REFERENCES}

1. Benjamin EJ, Blaha MJ, Chiuve SE, Cushman M, Das $S R$, Deo R, Floyd J, Fornage M, Gillespie C, Isasi CR, Jiménez MC. Heart disease and stroke statistics-2017 update: a report from the American Heart Association. Circulation 2017; 135(10): e 146-603.

2. McAloon CJ, Boylan LM, Hamborg T, Stallard N, Osman $F$, Lim $P B$, Hayat $S A$. The changing face of cardiovascular disease 2000-2012: An analysis of the world health organisation global health estimates data. Int J Cardiol 2016; 224: 256-264.

3. Bei Y, Yang T, Xiao J. Cardiovascular medicine in China: what can we do to achieve the Healthy China 2030 plan? BMC Med 2018; 16(1): 132.

4. Ma L, Wang W, Wu Y, Chen W. A12514 Outline of the Report on Cardiovascular Diseases in China, 2017. J Hyperten 2018; 36: e322.

5. Mopuri R, Pulaganti M, Kareem MA, Islam MS, KR DG, Irene $M, L U Y$, Kodidhela $L D$. Molecular assessment of protective effect of Vitex negundo in ISO induced myocardial infarction in rats. Biomed Pharmacother 2017; 92: 249-253.

6. Li $H$, Song $F$, Duan LR, Sheng JJ, Xie YH, Yang $Q$, Chen $Y$, Dong QQ, Zhang BL, Wang SW. Paeonol and danshensu combination attenuates apoptosis in myocardial infarcted rats by inhibiting oxidative stress: Roles of Nrf2/HO-1 and PI3K/Akt pathway. Sci Rep 2016; 6: 23693.

7. Sun X, Li C, Lu J. Protective effect of ginsenoside Rd against isoproterenol-induced myocardial infarction in Wistar rats. Trop J Pharm Res 2019; 18(1): 93-100.

8. Liu J, Chen L, Lu H. Cardioprotective effect of salvianolic acid $B$ against isoproterenol-induced inflammation and histological changes in a cardiotoxicity rat model. Trop $J$ Pharm Res 2018; 17(11): 2189-2197.

9. Rhee KJ, Lee CG, Kim SW, Gim DH, Kim HC, Jung BD. Extract of Ginkgo Biloba ameliorates streptozotocininduced type 1 diabetes mellitus and high-fat dietinduced type 2 diabetes mellitus in mice. Int $\mathrm{J}$ Med Sci 2015; 12(12): 987.

10. Jiang $Y X$, Li W, Wang GG, Zhang WQ, Lv YC, Sun $T$. Improvement of ginkgolide $B$ on diabetic nephropathy in streptozotocin (STZ)-induced rats. Int J Clin Exp Med 2018; 11(12): 13347-13355.

Trop J Pharm Res, January 2020; 19(1): 68 
11. Grypioti AD, Kostopanagiotou G, Demopoulos CA, Roussos A, Mykoniatis M. Platelet activating factor (PAF) antagonism with ginkgolide $B$ protects the liver against acute injury. Importance of controlling the receptor of PAF. Dig Dis Sci 2008; 53(4): 1054-1062.

12. Xia SH, Fang DC. Pharmacological action and mechanisms of ginkgolide B. Chin Medical J 2007; 120(10): 922-928.

13. Guo C, Zhang J, Zhang P, Si A, Zhang Z, Zhao L, Lv F, Zhao G. Ginkgolide $B$ ameliorates myocardial ischemia reperfusion injury in rats via inhibiting endoplasmic reticulum stress. Drug Des Dev Ther 2019; 13: 767.

14. Zhang $R$, Xu L, Zhang $D$, Hu B, Luo Q, Han D, Li J, Shen

C. Cardioprotection of Ginkgolide $B$ on myocardial ischemia/reperfusion-induced inflammatory injury via regulation of A20-NF-KB pathway. Front Immunol 2018; 9.

15. Gu JH, Ge JB, Li M, Wu F, Zhang W, Qin ZH. Inhibition of NF-KB activation is associated with anti-inflammatory and anti-apoptotic effects of Ginkgolide $B$ in a mouse model of cerebral ischemia/reperfusion injury. Eur $J$ Pharma Sci 2012; 47(4): 652-660.

16. Gao J, Chen T, Zhao D, Zheng J, Liu Z. Ginkgolide $B$ exerts cardioprotective properties against doxorubicininduced cardiotoxicity by regulating reactive oxygen species, Akt and calcium signaling pathways in vitro and in vivo. PloS One 2016; 11(12): e0168219.
17. National Research Council. Guide for the care and use of laboratory animals. National Academies Press; 8th Ed, 2010 Dec 27.

18. Li W, Qinghai S, Kai L, Xue M, Lili $N$, Jihua $R$, Zhengxiang L, Xiaoling L, Di G, Qi Y, Mengyun D. Oral administration of Ginkgolide $B$ alleviates hypoxiainduced neuronal damage in rat hippocampus by inhibiting oxidative stress and apoptosis. Iran J Basic Med Sci 2019; 22(2): 140.

19. Venge $P$, van Lippen L, Blaschke S, Christ M, Geier F, Giannitsis E, Hagström E, Hausfater $P$, Khellaf M, Mair $J$, et al. Equal clinical performance of a novel point-ofcare cardiac troponin I (cTnl) assay with a commonly used high-sensitivity cTnl assay. Clin Chim Acta 2017; 469: 119-125.

20. Feng Z, Yang $X$, Zhang L, Ansari IA, Khan MS, Han S, Feng $Y$. Ginkgolide $B$ ameliorates oxidized low-density lipoprotein-induced endothelial dysfunction via modulating Lectin-like ox-LDL-receptor-1 and NADPH oxidase 4 expression and inflammatory cascades. Phytother Res 2018; 32(12): 2417-2427.

21. Vriend J, Reiter RJ. The Keap1-Nrf2-antioxidant response element pathway: a review of its regulation by melatonin and the proteasome. Mol Cell Endocrinol 2015; 401: 213-220. 